\title{
LA AUSENCIA DE DIVISIÓN DE PODERES EN EL MUNICIPIO. UNA DEBILIDAD EN EL FEDERALISMO MEXICANO
}

\author{
THE ABSENCE OF DIVISION OF POWERS IN THE \\ MUNICIPALITY. A WEAKNESS IN MEXICAN FEDERALISM
}

\author{
SAÚl Moisés Ríos LuVIANO \\ Universidad Anáhuac Cancún, México \\ saulmoises@hotmail.com
}

\section{RESUMEN:}

El federalismo como proyecto de vida que, organizado como forma de gobierno, tiene instituciones democráticas y representativas, el cual se nutre con la existencia de gobiernos autónomos que están dotados de personalidad jurídica, administrativa y política, como es el caso de México. El presente texto hace una revisión sobre el federalismo mexicano, el cual presenta una debilidad por tener ausencia de división de poderes en el orden de gobierno más cercano al ciudadano. Se describe cómo en el municipio el poder absoluto político-administrativo recae de forma práctica acompañada de una ambigüedad jurídica en una sola persona, el presidente municipal, quien hace las funciones de ejecutivo, legislativo e incluso judicial. Esa ausencia de división de poderes en el orden de gobierno municipal debilita al federalismo mexicano, lo que justifica su centralismo excesivo.

\section{Palabras clave:}

Federalismo, Gobierno Local, Municipio, División de Poderes y Relaciones Intergubernamentales.

\section{ABSTRACT:}

Federalism as a life project, as well as a tool to organize a government, has democratic institutions whose main role is to represent its people. In the case of 
Mexico, federalism is also empowered by the existence of governments with autonomous jurisdictions, administrative and political principles. This paper aims at analyzing the principal practices of federalism in Mexico, where some weaknesses are evident enough as it can be seen how power is whether present or absent in different levels of the government, let alone in those which are closer to the citizens. It is described how the political and administrative power and rules in a municipality are put into practice in an ambiguous legal way by a single person: The Mayor. This person usually plays different roles, since he is not only at the top of the executive, but also of the legislative and judicial powers in the community. This situation in the municipal governments has not just weakened the federalism in Mexico, but it also justifies a harmful centralism in the country.

\section{Keywords:}

Federalism, local government, municipality, separation of powers and intergovernmental relations.

\section{INTRODUCCIÓN}

Conceptuar o definir al municipio no es tarea fácil, existen considerables trabajos que abordan la temática sin aún poder llegar a un consenso. El tema se complica más cuando hablamos del municipio en un federalismo como proyecto de vida y organizado como forma de gobierno.

México vive un federalismo donde existen instituciones democráticas y representativas a través de tres órdenes de gobiernos autónomos, que están dotados de personalidad jurídica, administrativa y política. Los tres órdenes de gobierno son: municipal, estatal y federal. Ninguno se encuentra supeditado al otro, cada uno tiene su espacio territorial, su gobierno emanado de forma democrática y con autonomía jurídica, administrativa y presupuestaria.

El presente texto se centra en el orden de gobierno municipal porque es el espacio de identidad del ciudadano con su territorio, del primer contacto con su entorno y con su realidad, el espacio donde hace los reclamos sociales por sus demandas y necesidades. Sobre todo, es la célula básica territorial y administrativa de la conformación social, económica y política del país, constituida por territorio, población y gobierno. Es la institución jurídica, política y social que tiene como finalidad organizar a una comunidad en la gestión autónoma de sus intereses de convivencia primaria y vecinal, regida por un Ayuntamiento.

Por lo anterior, es de importancia realizar una revisión sobre la práctica del federalismo mexicano, el cual presenta una debilidad por tener ausencia de división de poderes en el orden de gobierno más cercano al ciudadano.

Se describe cómo en el municipio el poder absoluto político-administrativo recae de forma práctica acompañada de una ambigüedad jurídica en una sola persona, el presidente municipal, quien hace las funciones de ejecutivo, legislativo e incluso judicial. Esa ausencia de división de poderes en el orden de gobierno municipal debilita al federalismo mexicano, lo que justifica su centralismo excesivo. 
Se concluye que es necesaria una reforma constitucional para darle más claridad al federalismo mexicano a través de la división de poderes en cada uno de los tres órdenes de gobierno, principalmente en el municipio donde jurídicamente no está definida la división.

\section{FEDERALISMO, UN ACERCAMIENTO TEÓRICO}

El federalismo es una forma de organización del sistema político basado en una distribución funcional y territorial del poder entre un ámbito central y ámbitos locales (estados, provincias o territorios independientes o federados), los cuales participan de un pacto que se sustenta en la Constitución. El federalismo es una forma de organización institucional que en teoría garantiza la descentralización política y administrativa, a la vez que crea un poder soberano (el gobierno federal) en el que las sociedades locales se encuentran representadas por ser el gobierno de la nación, del que forman parte. ${ }^{1}$

Como se señaló anteriormente, en lo que respecta al federalismo, es un arreglo político-institucional que implica una distribución de territorio y de funciones. A pesar de las diferencias, lo común en los Estados federales es entonces: 1) la existencia de un pacto o arreglo institucional entre ámbitos o poderes; 2) la subordinación de poderes y entidades a la Constitución, cuya modificación sólo puede hacerse con la intervención de representantes especiales de los pueblos que integran el Estado; y 3) el garantizar la autonomía y equilibrio entre ámbitos de gobierno federal y estatal en el que ningún poder está por encima de otro. ${ }^{2}$

Entonces podemos entender por federalismo, un proyecto de vida política que, organizado como forma de gobierno, tiene como sustento instituciones democráticas y representativas que dan cuerpo a relaciones de poder que permiten la cohesión en la acción de gobierno, dado que ésta se nutre con la existencia de centros autónomos que están dotados de personalidad jurídica y política. ${ }^{3}$

También es cierto teóricamente que se trata de una forma de organización institucional que persigue la descentralización política y administrativa del aparato gubernamental, creando un poder soberano (el gobierno federal) en el que las entidades locales se encuentran representadas, a la vez que son soberanas en sus territorios y sociedades. ${ }^{4}$

Rodolfo García del Castillo afirma que por lo que hace al concepto de federalismo, su delimitación teórica puede emprenderse desde distintas perspectivas.

1 MARTÍNEZ, Carlos Assad. "Límites y posibilidades para la descentralización de las políticas sociales" En: CORDERA, Rolando y ZICCARDI, Alicia (Coord.) Las políticas sociales de México al fin del milenio. Descentralización, diseño y gestión. Coordinación de Humanidades, Facultad de Economía, Instituto de Investigaciones Sociales UNAM-Miguel Ángel Porrúa. México, 2000.

2 ZICCARDI, Alicia. "El federalismo y las regiones: una perspectiva municipal" En: Gestión y Política Pública, II Semestre, Vol. 12, Núm. 2. Centro de Investigación y Docencia Económicas, Miguel Ángel Porrúa. México, 2003.

3 UVALLE BERRONES, Ricardo. Descentralización política y federalismo: consideraciones sobre el caso de México. Centro Nacional de Desarrollo Municipal, 2004.

4 ZICCARDI, Alicia. "El federalismo y las regiones: una perspectiva municipal"... p. 35. 
Una forma inicial que puede resultar útil, consiste en recuperar la idea de reglas o normas sobre las cuales se montará el aspecto dinámico de cristalización de políticas concretas. "Federalismo es un sistema de reglas para la división de responsabilidades de política pública entre un número de agencias gubernamentales autónomas". 5

Ricardo Uvalle Berrones afirma que la descentralización se caracteriza por ser un modo de articular la coordinación política y administrativa del Estado nacional. Y el federalismo es una forma de gobierno que responde, a que las partes sean la base que permita la convivencia armónica del todo. El federalismo conjuga simultáneamente relaciones centrales y descentralizadas. Pero se trata de una conjugación de relaciones donde lo óptimo no es el equilibrio puro o abstracto del poder, sino una configuración calculada, balanceada y correlacionada de poderes que garanticen la diversidad política y cultural en favor de la unidad del Estado, para acrecentar la vida civil de la sociedad y la expresión pública de las organizaciones ciudadanas. ${ }^{6}$

También es un medio para integrar la vida política de un país y fórmula para que las cuotas de poder sean regidas mediante acuerdos, reglas, potestades y el reconocimiento de autoridades supremas. El federalismo en la vida moderna da vida a un conjunto de poderes que deben dirigirse, coordinarse y colaborar a la manera de un todo armónico. El federalismo es un modo de organizar y ejercer el poder en el estado de derecho, respetando la autonomía y la capacidad de gestión de los gobiernos constituidos. ${ }^{7}$

El federalismo en cuanto sistema de convivencia no es ajeno a las relaciones de conflicto y cooperación. Pero tiene vías razonables para que la acción de gobierno pueda aspirar al consenso y la legitimidad. Por factores geográficos y políticos, los ámbitos centrales, estatales, municipales y comunales cuidan intereses propios de su representación. Por ello, no significa que interdependencia en la acción de gobierno no pueda lograrse. De esta forma, es posible hablar de dinámica e interacción, considerando entonces el federalismo como un proceso, un movimiento perpetuo que oscila entre la diversidad y la unidad, la descentralización y la descentralización. ${ }^{8}$

La finalidad de revisar el término federalismo es llegar a una idea que sea funcional a los propósitos del presente texto, por lo que recuperaremos varias y se integraran a lo largo del texto. México tiene una organización institucional dividida en tres órdenes de gobierno: municipal, estatal y federal, donde cada uno tiene federalizadas sus funciones y obligaciones.

\footnotetext{
5 GARCÍA DEL CASTILLO, Rodolfo. Los municipios en México: los retos ante el futuro. Centro de Investigación y Docencia Económicas, Miguel Ángel Porrúa. México. 1999.

6 UVALLE BERRONES, Ricardo. Descentralización política y federalismo: consideraciones sobre el caso de México. Centro Nacional de Desarrollo Municipal. 2004.

7 UVALLE BERRONES, Ricardo. Descentralización política y federalismo: consideraciones sobre el caso de México... p. 56

8 UVALLE BERRONES, Ricardo. Descentralización política y federalismo: consideraciones sobre el caso de México... p. 57
} 
En los tiempos actuales los temas políticos, económicos, sociales y culturales giran en torno a un mundo globalizado y al abordar el gobierno local, pudiera considerarse que estamos entrando en un terreno de menor importancia. Sin embargo, es en este contexto, cuando el gobierno local tiene mayor relevancia, al encargarse de resolver los pequeños problemas de cada día y al mismo tiempo fortaleciendo al Estado-nación que se ve tan debilitado por el impacto de la globalización y sus crecientes problemas supranacionales.

Las tendencias hacia procesos de globalización económica, social y política evidencian nuevas formas de organización de las sociedades. No obstante, junto a estas tendencias que apuntan a procesos de carácter global, la corriente conocida como localismo señala las potencialidades del espacio local en los procesos de reestructuración política, económica y social que se están produciendo en las sociedades contemporáneas, así como en la redefinición del papel de los gobiernos locales en las transformaciones de la sociedad.

Si se hiciera la pregunta ¿cuáles serían los rasgos esenciales que dan consistencia a la idea de un gobierno local mexicano?; en primer lugar, opera en un área geográfica limitada dentro de la nación; en segundo lugar, funciona con mecanismos de selección de líderes por medio de elecciones periódicas; y finalmente disfruta de una cierta autonomía, aunque este concepto es complejo y hace referencia a tres conjuntos de valores: libertad-autonomía, democracia-participación y eficiencia.

Entonces se responde la pregunta afirmando que en México la idea de un gobierno local hace referencia al municipio como base de la división territorial, política y administrativa del país. Por lo tanto, en este trabajo, como gobierno local se refiere al municipio, sin antes dejar claro que no son sinónimos, sino lo más cercano para el caso mexicano.

Para los fines del presente texto materializamos al gobierno local en el municipio, porque es un elemento clave en el sistema político mexicano por varias razones: en primer lugar, el municipio es el ámbito más próximo a los ciudadanos y a los intereses territorialmente considerados. En segundo lugar, a pesar de su heterogeneidad (diferente tamaño, diferente estructura social, diferentes necesidades, etcétera), proporciona y gestiona una serie de servicios fundamentales para el bienestar de los ciudadanos. En tercer lugar, el conjunto de municipios supone un porcentaje importante del total del gasto público y del empleo del país. En cuarto lugar, es un ámbito especialmente relevante en lo que concierne a la participación política y a la expresión de intereses políticos. Finalmente, los municipios juegan un papel estratégico en la construcción de la legitimidad en el desarrollo y reforzamiento de las nuevas estructuras y prácticas democráticas. ${ }^{9}$

Coincidiendo con el mismo autor, es importante señalar que los gobiernos locales en el actual proceso de globalización han tenido la necesidad de generar

9 ALBA CARLOS R. El sistema político local: Un nuevo escenario de gobierno, Madrid, Universidad Carlos III de Madrid. 1999. 
toda una serie de dinámicas y complejos proceso de gestión, con el objeto de dar respuesta a la nuevas funciones, prestar los servicios y de afrontar los retos que les plantea la sociedad, de ello a veces sin contar con unas estructuras administrativas suficientes para asumir las nuevas tareas, muchas de las cuales requieren un planteamiento que va más allá de la mera administración.

Entonces el papel que corresponde a los municipios es consolidar el modelo de gobierno local autónomo como esfera separada de los demás, e ir hacia un modelo de municipio integrado y participativo en todo el proceso político global. Además, la presencia de gobiernos locales con suficiente autonomía maximiza los deseos de los ciudadanos, ayuda a los procesos de innovación, estimula la participación y dinamiza el pluralismo político.

Por otra parte, es importante tener una visión histórica del municipio como institución, por lo que Jacinto Faya Biseca dice que el municipio es un producto histórico y no el resultado de una fría construcción doctrinaria, cambiante y diverso a través de la historia. El municipio no responde no ha respondido ni responde a las mismas necesidades de una manera igual y uniforme en las distintas geografías del mundo y en los diversos tiempos históricos. Esta institución es afectada muy sensiblemente, según sea la connotación y el valor que un Estado le otorgue a las cuestiones sociológicas, políticas y jurídicas. Prácticamente, son estos valores los que determinan la concepción política del municipio como una institución histórica. ${ }^{10}$

De igual forma, el municipio constituye la comunidad asentada en un territorio. En cuanto a comunidad tiene tradición cultural estructurada: dotada de la capacidad de generar constructos sociales y políticos para alcanzar sus fines, y además es referente de habitantes, propios y extraños. Es en los espacios locales donde cristalizan las experiencias individuales que abren paso a la acción colectiva para construir un referente social. ${ }^{11}$

Por su parte, Moisés Ochoa Campos define al municipio como: la forma, natural — como comunidad básica de personas avecindadas dentro de un territorio y que cuenta con una organización para la atención de sus requerimientos comunes - y política —ámbito de gobierno del sistema político, donde juega un papel en el desarrollo económico y social del país - a la vez, de organización de la vida colectiva, capaz de asegurar bajo una forma democrática, el ejercicio total de la soberanía popular. ${ }^{12}$

\section{LA CONCEPCIÓN DE MUNICIPIO: DELIMITACIONES PARA EL CASO MEXICANO}

Para el caso de México el municipio es un orden de gobierno, donde su población tiene capacidad para autogobernarse por leyes en las que se plasman

\footnotetext{
$\overline{10}$ FAYA BISECA, Jacinto. "Visión histórica del municipio como institución política" En: VEGA HERNÁNDEZ Rodolfo (Coor.) Municipio: Aspectos politicos y administrativos, Fundación Universitaria de Derecho, Administración y Política, S. C. 2002.

11 BAZDRESCH PARADA, Miguel. Naturaleza del municipio y la agenda para renovarlo. Centro de Investigación y Formación Social del Instituto Tecnológico de Estudios Superiores de Monterrey (ITESO). México. 2000.

12 OCHOA CAMPOS, Moisés. La reforma municipal, México, Miguel Ángel Porrúa. 1968.
} 
las aspiraciones, los fines que se pretenden alcanzar, las actividades que se deben realizar: se establecen los órganos de gobierno, las atribuciones de cada uno, así como los requisitos que deberán cumplir los ciudadanos que integren esos órganos.

En la Constitución de los Estados Unidos Mexicanos, artículo 115, el municipio es un ente autónomo que reúne las siguientes características: personalidad jurídica propia, patrimonio propio, no tiene vínculos de subordinación y jerarquía con el gobierno del estado, administra libremente su hacienda, tiene facultades reglamentarias, ejecutivas y judiciales, y su gobierno es electo popularmente.

De acuerdo a lo anterior, la naturaleza del municipio, se encuentra estrechamente ligada a aspectos fundamentales sociales, políticos y administrativos. Por lo que, al hablar de municipio, se hace referencia, por un lado, a una comunidad cohesionada por fenómenos de agregación, de cultura, de sociabilidad, inscrita en un cúmulo de relaciones de intercambio para conseguir su permanencia y crecimiento, y por otro, a un espacio político asociado a un referente administrativo e institucional.

Rodolfo García del Castillo en su libro Los Municipios en México. Los retos ante el futuro, afirma que es necesario considerar los siguientes espacios como propios del municipio: a) espacio de gobierno, donde el municipio es una agrupación con carácter de corporación de derecho político y como tal participa en la administración pública, el Estado le otorga facultades que lo autorizan y, a veces, le obligan también a realizar tareas de la comunidad local con independencia y bajo su propia responsabilidad, adoptando la forma de poder coactivo; b) espacio geográfico, el municipio es la circunscripción territorial más pequeña del país y está bajo el gobierno inmediato y directo del ayuntamiento; c) comunidad - espacio social, espacio cultural-, es una comunidad asentada en un territorio, que cuenta con una capacidad jurídica y patrimonio propio al que se le reconocen derechos suficientes para atender las necesidades de su población y para organizarse libre y democráticamente; y d) espacio económico, una institución de la administración pública local encargada de efectuar la gestión de recursos, formulación e implementación de política, en un territorio dado y en interacción constante con su comunidad. En su operación cotidiana la institución municipal actúa como una organización inscrita en las relaciones inter e intragubernamentales que transitan a través de un orden federal. ${ }^{13}$

Es necesario dejar claro que el municipio mexicano se autogobierna por sus propios vecinos, a través de un Ayuntamiento que es un órgano de gobierno colegiado que toma sus propias decisiones por deliberación y mayoría de votos, cuyos integrantes son: presidente municipal, síndico y varios regidores, de acuerdo a lo establecido en cada legislación estatal, designados por sufragio popular, libre, secreto y directo a través de los principios de mayoría relativa y representación proporcional. Todas las competencias delegadas al municipio serán ejercidas por el Ayuntamiento de manera exclusiva. ${ }^{14}$

13 GARCÍA DEL CASTILLO, Rodolfo. Los municipios en México: los retos ante el futuro... p. 76.

14 ROBLES MARTÍNEZ, Reynaldo. El municipio, México 4ª edición. Miguel Ángel Porrúa. 2000. 


\section{LA COORDINACIÓN INTERGUBERNAMENTAL EN EL FEDERALISMO MEXICANO}

Estudiar el fenómeno del federalismo considerando únicamente aspectos formales de competencias y relaciones entre poderes (ejecutivo, legislativo y judicial) y esferas de gobierno (federal, estatal y municipal) tiene claras limitaciones. Una perspectiva de ese tipo tiende a agotar su validez explicativa cuando se aplica para el análisis de situaciones dinámicas, pues, durante el estudio de las políticas concretas, aparecen recurrentes los problemas asociados al poder y los procesos decisorios como piezas clave para funcionamiento del sistema político. ${ }^{15}$

Es difícil entender el marco de funcionamiento y la eficacia de los gobiernos locales, así como su contribución a la dinámica general de un país, sin conocer con precisión el tipo de coordinación intergubernamental existente. El propio concepto hace referencia a un conjunto, extraordinariamente variado, de actividades e interrelaciones entre unidades de gobierno de todo tipo y de diferentes ámbitos territoriales. Quiere decir que, siendo el marco jurídico-normativo importante para determinar las condiciones del ejercicio del poder y la distribución de competencias, difícilmente comprenderíamos que gran parte de las interrelaciones se producen al margen de los límites formales o, al menos, dentro del ejercicio de los espacios de discrecionalidad que la legislación permita. ${ }^{16}$

En lo respecta a México, la coordinación intergubernamental es un tema relativamente nuevo, debido a que las relaciones tradicionales entre los municipios, los estados y la federación se han regido por una jerarquización estricta de arriba hacia abajo. En las últimas décadas, el progreso hacia la democratización y descentralización del país ha abierto a los municipios la oportunidad de empezar a definir los espacios gubernamentales y administrativos en aquellos en que la comparten o la ceden a otros órdenes de gobierno. Así, desde el punto de vista de los municipios, el fondo del debate sobre la coordinación intergubernamental es un incremento sustancial de la importancia de los mismos en el gobierno del país.

Rodolfo García del Castillo afirma que las relaciones intergubernamentales ofrecen la posibilidad de considerar diversos aspectos, en espacios de gobierno distintos, para explicar el comportamiento complejo seguido por los actores, en la manipulación de los elementos y recursos diversos para concretar acciones públicas. El autor cita tres modelos o enfoques para el estudio de las relaciones intergubernamentales:

1. Modelo de autoridad coordinada. En el cual se da una distinción y separación clara entre el gobierno nacional y el gobierno de los estados. Los municipios siempre son incluidos dentro y dependen de los gobiernos de los estados.

2. Modelo de autoridad traslapada o superpuesta. En éste existen áreas o espacios de gobierno donde coinciden parcialmente entre sí los tres

15 GARCÍA DEL CASTILLO, Rodolfo. Los municipios en México: los retos ante el futuro... p. 78.

16 ALBA, Carlos R. El sistema político local: Un nuevo escenario de gobierno, ... p. 28. 
órdenes. Las relaciones que se dan son interdependientes y el patrón de autoridad es la negociación.

3. Modelo de autoridad inclusiva. En este modelo las relaciones de autoridad son jerárquicas y supone que el gobierno federal busca expandir su proporción de poder ejerciendo sobre los estados y los municipios. Para lograrlo hay dos estrategias posibles: una es reducir los poderes y competencias de los estados o municipios o de ambos; la segunda es hacer crecer el circulo de poder del gobierno federal fuera o más allá de las competencias de estados y municipios, esto sin afectarlas. ${ }^{17}$

Las relaciones intergubernamentales incluyen las vinculadas al ejercicio del poder o determinadas competencias, relaciones financieras (especialmente la transferencia de fondos y otros recursos y las condiciones de su utilización) y, finalmente, redes de influencia entre las unidades implicadas y que contemplarían todos los mecanismos de información, negociación, coordinación, persuasión, etcétera. $^{18}$

\section{UNA DEBILIDAD EN EL FEDERALISMO MEXICANO}

Después de revisar con detalle la concepción teórica del federalismo, así como el federalismo real en México, el tema del gobierno local, el municipio y las relaciones intergubernamentales se vuelve interesante mencionar que en México existe una fuerte debilidad del federalismo y casualmente recae en el gobierno municipal esa debilidad que afecta a todo el sistema jurídico, político y administrativo.

Como se mencionó con anterioridad, en la Constitución de los Estados Unidos Mexicanos en el artículo 115 se hace referencia al municipio como orden de gobierno del sistema federal y ahí se explican sus atribuciones y obligaciones explicitas e implícitas. ${ }^{19}$

Para explicar en qué consiste la debilidad que se menciona, es necesario mencionar que en México se establece la división de poderes en cada orden de gobierno, en tres poderes, el legislativo, ejecutivo y judicial. Esa división se encuentra de forma explícita en la Carta Magna para el orden de gobierno federal y para los estados, pero no así para los municipios.

Para el caso del gobierno federal se explica de la siguiente forma la división de poderes: el poder ejecutivo recae en la figura del Presidente de la República, el cual, el ejercicio es unipersonal; el poder legislativo recae en el H. Congreso de la Unión, el cual se compone de dos cámaras, una de Diputados y otra de Senadores; y el poder judicial recae en la Suprema Corte de Justicia de la Nación y se integra por once Ministros.

17 GARCÍA DEL CASTILLO, Rodolfo. Los municipios en México: los retos ante el futuro... p. 80

18 ALBA, Carlos R. El sistema político local: Un nuevo escenario de gobierno,... p. 30.

19 CONSTITUCIÓN POLÍTICA DE LOS ESTADOS UNIDOS MEXICANOS. Cámara de Diputados, H. Congreso de la Unión. 2020. Consultado en: http://www.diputados.gob.mx/LeyesBiblio/ref/cpeum.htm 
Cada uno de los poderes del gobierno federal se plasma en la Constitución que son completamente autónomos e independientes e incluso son contrapeso entre cada uno de ellos para el ejercicio del poder, tal y como en su momento lo planteó Montesquieu.

Para el caso de los estados, se reproduce la misma lógica de la división de poderes: el poder ejecutivo recae en la figura del Gobernador, el cual el ejercicio es unipersonal; el poder legislativo recae en el H. Congreso del Estado, el cual se compone en un determinado número de diputados según la cantidad de población; y el poder judicial recae en el Tribunal Superior de Justicia y se integra por magistrados.

De igual forma, los poderes del gobierno estatal se plasman en la Constitución que son completamente autónomos e independientes e incluso son contrapeso entre cada uno de ellos para el ejercicio del poder. Aunque no está de más mencionar que en la práctica en todas las entidades federativas el poder ejecutivo somete a los otros dos poderes, tema de estudio y análisis para otras investigaciones.

El problema aparece cuando observamos la división de poderes en el gobierno municipal: el poder ejecutivo recae en la figura del Presidente Municipal, el cual el ejercicio es unipersonal; el poder legislativo recae en el H. Ayuntamiento, el cual se integra por el propio presidente municipal, síndico y regidores, donde incluso, quien cita a sesión, pone el orden del día, tiene voto de calidad e impone sanciones, es el presidente municipal; y el poder judicial no existe en el orden de gobierno municipal, a lo más que llega, es a tener un juez calificador para las faltas administrativas. Todo lo relacionado a los asuntos judiciales se remiten al poder judicial de los otros dos órdenes de gobierno, el estado o la federación.

Con lo mencionado anteriormente se observa un gobierno municipal con serias limitaciones en la propia división de poderes. El andamiaje jurídico mexicano desde la propia Constitución Federal, las Constituciones estatales, las leyes y reglamentos reproducen esas limitaciones y hacen legal incluso, el ejercicio del poder absoluto a una sola persona, el Presidente Municipal.

El Presidente Municipal tiene bajo su poder toda la administración pública municipal, es decir, el poder económico, el poder de la fuerza pública (la policía municipal) y en la práctica, pero además de forma legal, es quien preside el poder legislativo, el H. Ayuntamiento. Lo que él decida, es lo que se aprueba, el Ayuntamiento sólo avala y legaliza sus propuestas, es muy complicado que se pongan en contra de sus ideas e incluso ocurrencias.

Lo anterior tiene su origen en elección democrática que realizan los ciudadanos, esa elección la hacen a través de planillas donde figura principalmente el presidente y muy poco el síndico y los regidores. La planilla ganadora se convierte en mayoría dentro del Ayuntamiento, algunos de las planillas perdedoras se integran como representación proporcional de acuerdo al número de votos alcanzados en la elección, pero nunca podrán ser mayor al número de integrantes de 
la planilla ganadora, lo que permite al presidente municipal presentar y aprobar todas sus propuestas por mayoría, la oposición sólo legitima el proceso. ${ }^{20}$

Ante la situación anterior, los gobiernos municipales en México en la práctica son gobernados por "mini reyes" porque no existe una división de poderes, gobierna una sola persona sin contrapeso alguno. ${ }^{21}$ La normatividad le permite ejercer el poder de esa forma, lo que ha provocado la creación de cacicazgos legales a lo largo y ancho del país que empañan el federalismo mexicano.

Con esa debilidad jurídica, política y administrativa en el federalismo mexicano se justifica de forma implícita por varios estudiosos y políticos que no es correcto descentralizar el poder a los órdenes de gobierno. A lo largo de la historia del federalismo mexicano, el poder y los recursos se han ejercido de forma centralizada en el gobierno federal. El avance en la descentralización se ha realizado hacia los gobiernos estatales, aunque en una pequeña porción. Es importante resaltar que en los últimos años, se ha retrocedido en esa anhelada descentralización por la corrupción en el manejo de los propios estados. ${ }^{22}$

Principalmente se oponen a la descentralización hacia el gobierno municipal porque lo consideran el inexperto, el que no tiene las condiciones, el que es muy corrupto, el que no tiene el personal capacitado o profesional. Por esas condiciones, tanto el gobierno federal como los estados, utilizan a los gobiernos municipales como un instrumento coadyuvante para implementar alguna política pública o programa social. En la mayoría de los casos no se les consulta para el diseño e instrumentación, sólo se le invita para la aplicación. Los gobiernos municipales por cierta comodidad lo han convertido en una forma de existencia justificada.

Es en esas condiciones, donde se recurre en el discurso de las relaciones intergubernamentales entre los tres órdenes de gobierno. Para ello, se justifica el actuar del gobierno municipal en la aplicación de un programa federal como esa relación intergubernamental. En la realidad el gobierno municipal —e incluso

20 En muy pocas ocasiones se han dado casos donde el síndico y regidores no le aprueban al presidente municipal sus propuestas. Esos casos obedecen más a diferencias personales o intereses de grupos que provocan una fractura en la unidad de la planilla ganadora. Aunque al final, en la mayoría de los casos, el presidente municipal por ser el ejecutivo y al mismo tiempo quien preside el legislativo del orden de gobierno municipal tiene más poder y termina sometiendo a quien se le oponga.

21 En algunos municipios de México la oposición y contrapeso real que tienen los presidentes municipales son los mismos ciudadanos que organizados exigen y se manifiestan para presionar al máximo jefe de la demarcación. Los otros dos poderes no figuran y no representa en la práctica ese contrapeso esperado para que gobierne de acuerdo a las necesidades reales del municipio. En algunos casos, uno que otro periodista hacen la función de contrapeso, al denunciar sus malas decisiones como gobernante. Es importante mencionar que la mayor parte de la prensa local está cooptada e incluso incorporada a la nómina municipal y hace la función de aduladora del gobernante en turno para influir en la percepción de los ciudadanos.

22 En la década de los ochentas se dio un proceso de descentralización hacia los estados del sector educativo, es decir, se le transfirió poder y recursos a los estados en temas de educación, cada estado estaba a cargo de la contratación y pago de los docentes de educación básica. Al paso de los años se fue corrompiendo de forma muy grave en cada estado, al grado que ya era ridículo y sobre todo insostenible la situación. En el gobierno del presidente Enrique Peña Nieto para enviar un mensaje de que estaba combatiendo actos de corrupción, se tomó la decisión de centralizar el pago de la nómina de todos los maestros del país, es decir, actualmente ya no lo hacen los estados, el recurso sale directamente de la Secretaria de Hacienda federal directo a los profesores de educación básica de todo del país. 
estatal — no participa en el diseño del programa y sólo coadyuva o colabora para su ejecución. Se convierte en un instrumento ejecutor.

Otra razón cómoda para los gobiernos municipales e incluso con ciertas ventajas jurídicas en lo económico, es cuando se realiza una obra pública en la geografía municipal e intervienen dos o tres órdenes de gobierno. El marco jurídico vigente establece que, cuando se realice una obra (carretera, alumbrado, cementerio, agua potable, etcétera) y los recursos provengan del gobierno del estado y el municipio, es decir, aportación bipartita, quien ejercerá el recurso será el gobierno municipal. Cuando las aportaciones de los recursos provengan de los tres órdenes de gobierno, es decir, tripartita, quien ejercerá, también es el municipio.

En ambos casos, bipartita y tripartita quien licita la obra es el H. Ayuntamiento con cierta supervisión y acompañamiento de los otros órdenes de gobierno. La idea es que esas obras además de traer un beneficio en específico, también generen una derrama económica para las empresas y trabajadores locales. Eso permite al presidente municipal adjudicarle la obra a determinada empresa tergiversando el proceso de licitación, el cual, termina siendo legal, aunque en la práctica no es ético, la mayoría de los casos existe un beneficio económico efectivo o en especie para el ejecutivo municipal.

En México es ampliamente conocido y además está documentado cómo se desarrolla esa práctica, mejor conocida como el diezmo de todas las obras públicas que se realizan. En el caso de los municipios, la persona directamente beneficiada es el presidente municipal. Es muy común observar y en cientos de casos documentados, que después de finalizar sus periodos constitucionales, sus fortunas económicas se ven considerablemente incrementadas.

La realidad es tan evidente que, incluso algunos personajes políticos tienen muy claro el poder y los recursos económicos que se puede ejercer siendo presidente municipal, por lo que prefieren abandonar puestos públicos que se considerarían de mayor prestigio o estatus político como son diputado federal, senador de la república, secretario de estado o diputado local, para buscar una presidencia municipal, la cual es más rentable política y económicamente.

Ante esa realidad imperante en el sistema federal mexicano, el federalismo funciona con cierta distorsión legal y práctica, donde no existe la clara división de poderes en el orden de gobierno más cercano al pueblo. En la praxis existe cierta comodidad política y conveniencia económica que ha permitido por décadas no replantear tal situación, aunque se tenga muy clara. Una es por no asumir más responsabilidades como orden de gobierno y sólo limitarse a coadyuvar con los otros tres; y la otra es por conveniencia económica de los aspirantes al puesto, porque permite el estatus de "mini rey" en su demarcación territorial sin el equilibrio de poderes o contrapesos.

Lo anterior refleja que esa debilidad del federalismo mexicano parece estar lejos de ser subsanada para alcanzar a plenitud un federalismo con división de poderes en sus tres órdenes de gobierno. Quienes pueden hacer esos cambios, el poder legislativo federal, los poderes legislativos e incluso los partidos políticos y actores políticos no muestran interés en hacerlo porque en el fondo esperan ellos 
mismos ocupar ese puesto en algún momento y aprovechar las ventajas del mismo para ejercer el poder y beneficiarse económicamente.

\section{RECOMENDACIONES Y CONCLUSIONES}

Después de haber revisado algunas definiciones y conceptos en el presente documento, se puede afirmar que aún no se ha terminado la búsqueda y conformación del marco teórico exacto para el análisis del federalismo y la descentralización hacia los gobiernos locales - gobiernos municipales - a pesar de la existencia de una gran variedad de producción teórica. Es necesario hacer uso de esos elementos teóricos existentes para ver hasta qué punto nos ayudan o no explicar una realidad especifica; porque no se trata de amontonar conceptos, definiciones, categorías de análisis y modelos, sin ponerlos en práctica. Se necesita avanzar en la compresión de los problemas que aquejan a la sociedad, pero también proponer soluciones.

El fortalecimiento del federalismo es una política prioritaria que tiene entre sus objetivos el desarrollo regional, mejorar los servicios públicos, abatir los costos administrativos y acercar las decisiones a los lugares donde éstas se requieren, para redistribuir la autoridad, las responsabilidades y los recursos del gobierno federal hacia los órdenes estatal y municipal.

El federalismo conlleva la necesidad de incrementar el poder administrativo y político del gobierno municipal, y de fortalecer sus capacidades de gestión con el objetivo de lograr una verdadera autonomía en la toma de decisiones, a través de la administración de recursos propios, y la aplicación eficaz de las medidas necesarias para afrontar las demandas de la población.

Con base en la reflexión presentada sobre la debilidad del federalismo mexicano por la ausencia de división de poderes en el orden de gobierno municipal, se propone que se haga una modificación en todo el andamiaje jurídico partiendo desde la Constitución Federal y se plasme de forma explícita y clara la división de poderes en el municipio, donde no quede un poder sometido al otro. Que se agregue el poder judicial al municipio donde existan jueces y su propio tribunal.

Se recomienda que el poder legislativo municipal sea modificado y funcione como en los otros órdenes de gobierno, que se convierta en un contrapeso al poder ejecutivo y el judicial. Es importante que no forme parte el presidente municipal del H. Ayuntamiento, que el síndico y los regidores sesionen sin la presencia de él, como hoy no sucede, y mucho menos que ponga el orden del día y tenga voto de calidad.

Se necesita que el H. Ayuntamiento cuente con su propio presupuesto para legislar y no dependa del ejecutivo, que no sea él quien les pague sus remuneraciones económicas y prestaciones, así como les otorgue algunos beneficios, como hoy sucede. La propuesta es que se convierta en un poder completamente independiente en lo político y económico.

Es indispensable que el $\mathrm{H}$. Ayuntamiento sea el poder que apruebe al presidente municipal su plan de gobierno, su presupuesto y sus programas. De igual 
forma que, lo pueda sancionar, que el presidente y sus funcionarios rindan cuentas ante el legislativo. Todo ello, sin ser parte del legislativo el ejecutivo, como hoy sucede.

Para lograr esa división de poderes en el municipio es necesario modificar todo el marco jurídico, como el proceso de elección democrática de las autoridades municipales. Los ciudadanos deben elegir por separado al ejecutivo (presidente municipal) y el legislativo (síndico y regidores). En el caso del poder judicial puede ser electo entre ejecutivo y judicial como sucede en los otros dos órdenes de gobierno, es decir, que el presidente municipal proponga y el $\mathrm{H}$. Ayuntamiento decida.

Es muy importante que exista un poder judicial con claras funciones en el orden municipal, el cual ahora es inexistente. Se necesita un poder que pueda determinar e incluso tomar la última decisión en el ámbito municipal si existiera controversia entre el ejecutivo y el legislativo. Al igual que el legislativo, se necesita de presupuesto propio y autonomía plena.

Se necesita que desde la célula básica de la organización política-administrativa de México se practique un auténtico federalismo con una verdadera división de poderes, ello permitirá consolidar la democracia, la toma de decisiones de forma colegiada y sobre todo con representatividad para que todos esos temas elementales que afectan al ciudadano sean atendidos por sus representados (síndicos y regidores).

No sólo se trata de modificar la normatividad y otorgarle esas facultades, sino hacerlo con los recursos correspondientes para que el orden de gobierno más cercano al ciudadano pueda determinar su propio futuro y su propio desarrollo y crecimiento como parte del Estado-Nación mexicano.

Por último, el reto es lograr gobiernos municipales con poder real, y que asuman ese poder con capacidad y responsabilidad. Como coordinadores y líderes locales de las gestiones de los recursos naturales, deberán convertirse en los catalizadores de las políticas públicas e intereses del desarrollo local sostenible. Por ello, resulta imprescindible la creación de mecanismos que permitan un balance entre las necesidades e intereses nacionales y las necesidades e intereses locales ¿cómo lograr ese balance? Es uno de los grandes retos en la implementación del federalismo en México.

\section{FUENTES DE CONSULTA}

ALBA CARLOS R. El sistema politico local: Un nuevo escenario de gobierno, Madrid, Universidad Carlos III de Madrid. 1999.

BAZDRESCH PARADA, Miguel. Naturaleza del municipio y la agenda para renovarlo. Centro de Investigación y Formación Social del Instituto Tecnológico de Estudios Superiores de Monterrey (ITESO). México. 2000.

CABRERO MENDOZA, Enrique y NAVA CAMPOS, Gabriela. Gerencia pública municipal conceptos básicos y estudios de caso, México, Centro de Investigación y Docencia Económicas, Miguel Ángel Porrúa. 2000. 

mara de Diputados, H. Congreso de la Unión. 2020. Consultado en: http:// www.diputados.gob.mx/LeyesBiblio/ref/cpeum.htm

FAYA BISECA, Jacinto. "Visión histórica del municipio como institución política" En: Vega Hernández Rodolfo (Coor.) Municipio: Aspectos políticos y administrativos, Fundación Universitaria de Derecho, Administración y Política, S. C. 2002.

GARCÍA DEL CASTILLO, Rodolfo. Los municipios en México: los retos ante el futuro. Centro de Investigación y Docencia Económicas, Miguel Ángel Porrúa. México. 1999.

LÓPEZ CHAN, Oscar Alfredo. El Ayuntamiento como agente del desarrollo local en un municipio semiurbano. El caso de Escárcega Campeche 1995-2000, Colegio Nacional de Licenciados en Administración. México. 2001

MARTÍNEZ, Carlos Assad. "Límites y posibilidades para la descentralización de las políticas sociales" En: Cordera Rolando y Alicia Ziccardi (Coord.) Las políticas sociales de México al fin del milenio. Descentralización, diseño y gestión. Coordinación de Humanidades, Facultad de Economía, Instituto de Investigaciones Sociales UNAM-Miguel Ángel Porrúa. México. 2000.

OCHOA CAMPOS, Moisés. La reforma municipal, México, Miguel Ángel Porrúa. 1968.

ROBLES MARTÍNEZ, Reynaldo. El municipio, México 4ª edición. Miguel Ángel Porrúa. 2000.

UVALLE BERRONES, Ricardo. Descentralización política y federalismo: consideraciones sobre el caso de México. Centro Nacional de Desarrollo Municipal. 2004.

ZICCARDI, Alicia. "El federalismo y las regiones: una perspectiva municipal" En: Gestión y Política Pública, II Semestre, Vol. 12, Núm. 2. Centro de Investigación y Docencia Económicas, Miguel Ángel Porrúa. México. 2003.

ZICCARDI, Alicia y MIER TERÁN, A. Pobreza urbana, programas de inclusión social y participación ciudadana. En T. Rendón Huerta, T. Guillén López y C. Paz Cuevas. Los Retos de la Democracia Local. El papel de los gobiernos municipales, indígenas y delegacionales en la superación de la pobreza y la desigualdad social. México: Universidad Nacional Autónoma de México, IGLOM. 2007. 